\title{
The influence of physical fitness on respiratory muscle strength in the elderly
}

\author{
Aline Patricia Bonato Miranda ${ }^{1, *}$, Ada Clarice Gastaldi ${ }^{2}$, Hugo Celso Dutra de Souza ${ }^{2}$, \\ Jair Licio Ferreira Santos ${ }^{3}$ \\ ${ }^{1}$ physiotherapist and doctoral graduate student of Ribeirão Preto Medical School, University of São Paulo (USP), Ribeirão Preto, São Paulo, \\ Brazil \\ ${ }^{2}$ Professor from the Physiotherapy course of the Department of Biomechanics, Medicine and Rehabilitation of the Locomotor System, \\ Ribeirão Preto Medical School, University of São Paulo (USP), Ribeirão Preto, São Paulo, Brazil \\ ${ }^{3}$ Professor from the Department of Social Medicine, Ribeirão Preto Medical School, University of São Paulo (USP), Ribeirão Preto, São \\ Paulo, Brasil
}

\section{Email address:}

apbmiranda@hotmail.com (A. P. B. Miranda), ada@fmrp.usp.br (A. C. Gastaldi), hugocds@fmrp.usp.br (H. C. D. de Souza), jlfs@fmrp.usp.br (J. L. F. Santos)

\section{To cite this article:}

Aline Patricia Bonato Miranda, Ada Clarice Gastaldi, Hugo Celso Dutra de Souza, Jair Licio Ferreira Santos. The Influence of Physical Fitness on Respiratory Muscle Strength in the Elderly. American Journal of Sports Science. Vol. 3, No. 1, 2015, pp. 6-12. doi: 10.11648/j.ajss.20150301.12

\begin{abstract}
Background: One of the consequences of aging process is the reduction in respiratory muscle strength. So, this study sought to determine the level of physical fitness that influences respiratory muscle strength among participants in a program for senior citizens. Methods: We evaluated 55 elderly between 60 and 80 years, of both sexes, with no history of respiratory disease. The participants were evaluated measuring the maximal in spiratory (MIP) and expiratory (MEP) pressures and applying the IPAQ questionnaire to assess their level of physical activity. The groups were compared using ANOVA test followed by Tukey's test with a significance level of 5\%. Results: $27.3 \%$ of the elderly were classified as active, $43.6 \%$ as irregularly active, and $29.1 \%$ as sedentary. The MIP values for the active $\left(82.7 \mathrm{cmH}_{2} \mathrm{O}\right)$ and irregularly active groups $(80.4$ $\left.\mathrm{cmH}_{2} \mathrm{O}\right)$ were higher than those observed for the sedentary group $\left(62.5 \mathrm{cmH}_{2} \mathrm{O}\right)(\mathrm{p}<0.05)$, and there was no significant difference between the active and irregularly active groups. Conclusion: This study demonstrated that more active elderly, regardless of the level or duration of activity, have higher inspiratory muscle strength than the sedentary ones.
\end{abstract}

Keywords: Elderly, Respiratory Muscle Strength, Physical Fitness

\section{Introduction}

The number of elderly people has progressively increased in recent decades (Paschoal, 2006 e Chaimowicz, 2006). According to a review produced by the Brazilian Institute for Geography and Statistics (Instituto Brasileiro de Geografia e Estatística - IBGE), those over 65 years of age represented $5 \%$ of the population. However, it is estimated that in 2050 , these two age groups will each represent $18 \%$ of the Brazilian population (IBGE, 2004). In the United States of America, individuals over 65 years of age represented $12.9 \%$ of the population by 2009 and will represent about $19 \%$ of the American population by 2030 (Census Bureau, 2009).

Aging causes a reduction in respiratory muscle strength, which is often accompanied by a decrease in the elastic recoil of the lungs and chest wall compliance (Huang et al., 2011). The respiratory muscles also show a decrease in type II fibers with age (Tolep et al., 1995 e nikolic et al., 2010), with a subsequent reduction in maximal respiratory pressures (maximal inspiratory and expiratory pressures, MIP and MEP, respectively), which reflects the integrated function of all of the respiratory muscles (Green et al., 2002).

These reductions associated with aging occur after 50 years of age and can interfere with coughing efficiency. These changes can also facilitate the occurrence of pathological processes, such as the accumulation of bronchial secretions and respiratory infections, which can interfere with the activities of daily living in elderly individuals (Papaléo 
Netto, 2002 e Freitas et al., 2010).

A study conducted by Tolep et al. (1995) found a $25 \%$ reduction in diaphragm strength among elderly individuals, according to measurements of diaphragmatic pressure during maximal voluntary inspiratory effort. These authors also suggested that alterations due to aging do not affect ventilation at rest but may lead to diaphragm muscle fatigue during exercise, when the respiratory muscles are more intensively recruited to maintain adequate levels of oxygenation.

In addition to physiological changes associated with aging, other factors, such as sedentary lifestyle, can affect muscle function (Jacob Filho; Souza, 1994 e Gorzoni; Russo, 2006). A sedentary lifestyle is directly related to the accelerated deterioration of functional and cardiorespiratory capacity in the elderly, which may cause significant changes in respiratory and other skeletal muscles and facilitate the accumulation of fat, the onset of cardiovascular diseases and the presence of anxiety and depression (Peluso; Andrade, 2005). Together, these changes lead to greater dependency and a loss of autonomy for elderly individuals (Cader et al., 2006).

One instrument that is used to quantify the physical activity level is the short version of the International Physical Activity Questionnaire (IPAQ), which is easy to use and has low associated costs. This questionnaire was developed to estimate the level of regular physical activity in groups and populations from different countries and socio-cultural backgrounds. Its development was proposed by the international consensus group on physical activity measurement under the seal of the WHO and with the involvement of 25 countries (Craig et al., 2003). The IPAQ was validated for Brazil in a study by Pardini et al. in 2001 .

Regular physical activity is known to have a "training effect" on respiratory muscles, which supports the preservation of their function. However, the minimal level of physical activity sufficient to reach these benefits, especially in the elderly population, remains unknown (Doherty, $2003 \mathrm{e}$ Nelson et al., 2007).

In this context, the quantification of respiratory muscle strength and the level of physical fitness in the elderly can be used to formulate exercise recommendations and identify more effective therapeutic measures. Thus, the objective of the present study was to determine the level of physical fitness that could influence respiratory muscle strength in participants in a program for senior citizens.

\section{Methods}

\subsection{Study Design}

This was a descriptive and analytical cross-sectional study that used a quantitative approach. The study design was developed at the School Health Center (Centro Saúde Escola - CSE) of the Claretian University Center (Centro Universitário Claretiano - CEUCLAR) in Batatais/SP, Brazil and was approved by the Research Ethics Committee of the
General Hospital of the School of Medicine of Ribeirão Preto (Hospital das Clínicas da Faculdade de Medicina de Ribeirão Preto - HCFMRP) under approval number 6420/08.

\subsection{Participants}

A total of 55 elderly individuals from the community (10 men and 45 women) who were participants in the Seniors project and the CSE from CEUCLAR in Batatais/SP, Brazil, were randomly selected, enrolled and evaluated. To be enrolled in the study, the elderly volunteers could be active or not active but needed to be between the ages of 60 and 80 years, independent and able to walk and enrolled at the CSE or a participant in the Seniors group at CEUCLAR. The exclusion criteria included smoking status, the presence of previous respiratory or cardiac disease, cognitive decline according to the Mini-Mental State examination (MMSE score $>20$ ) and the use of psychiatric medication that could interfere with the variables under study.

\subsection{Measurements}

\subsubsection{Assessment Procedures}

The participants signed the informed consent form, and after completing the MMSE for cognitive function, the participants were deemed able to complete the other questionnaires, because the application of this instrument (MMSE) was adopted in order to select individuals in a position to participate in the study, avoiding misinterpretation and bias in the result.

Subsequently, a questionnaire was applied to sociodemographic data developed by the researcher. The sociodemographic questionnaire included questions that briefly assessed gender, age, education, city of residence, mention of any cardiac or respiratory problems, smoking status, physical activity level and the use of medication. The IPAQ questionnaire was also completed to assess the level of physical activity of the study participants. Using the results of the questionnaire, the participants were divided into three groups according to physical activity level (active, irregularly active and sedentary).

\subsubsection{Measurement Protocols}

The MIP and MEP measurements were collected according to the American Thoracic Society guidelines (ATS, 2002), which are the most commonly used guidelines for assessing the strength of respiratory muscles. This protocol has been deemed easy to use because it is a simple method that delivers reliable reproducibility and it measures the strength of the respiratory muscles in general (Jardim; Ratto; Corso, 2002). The maximal respiratory pressures were evaluated using a compound gauge (Gerar () at an operating range of \pm $300 \mathrm{cmH}_{2} \mathrm{O}$, which was connected to a cylindrical acrylic piece, an $8-\mathrm{cm}$-long plastic breathing tube with a $2.4-\mathrm{cm}$ internal diameter and a hard plastic mouthpiece. Three training attempts were performed, and then, five technically satisfactory measures were obtained. At least two measures needed to be reproducible, with values that did not differ between one another by more than $10 \%$ of the higher value. 
The interval between measurements was one minute, and the highest value sustained for one second was selected. The participants were seated and relaxed for the measurements, and a nasal clip was used to avoid the loss of air. The MIP was measured from the residual volume, i.e., the participant performed a forced maximal inspiratory effort against the occluded airway after maximal expiration. The MEP was measured from the total lung capacity, i.e., the participant performed a forced expiratory effort against the occluded airway after maximal inspiration, ensuring that the buccinator muscles were not used (Silva; Rubim; Silva, 2000). For these measurements, the normal values according to Neder et al. (1999) were used.

The short version of the IPAQ was used, which was structured and applied as an interview. This test shows good validity and reproducibility coefficients, and the short version has the advantage of being practical and rapid and enabling efficient data collection (Pardini et al., 2001).

\subsection{Statistical Analysis}

The appropriate sample size was calculated in a pilot study

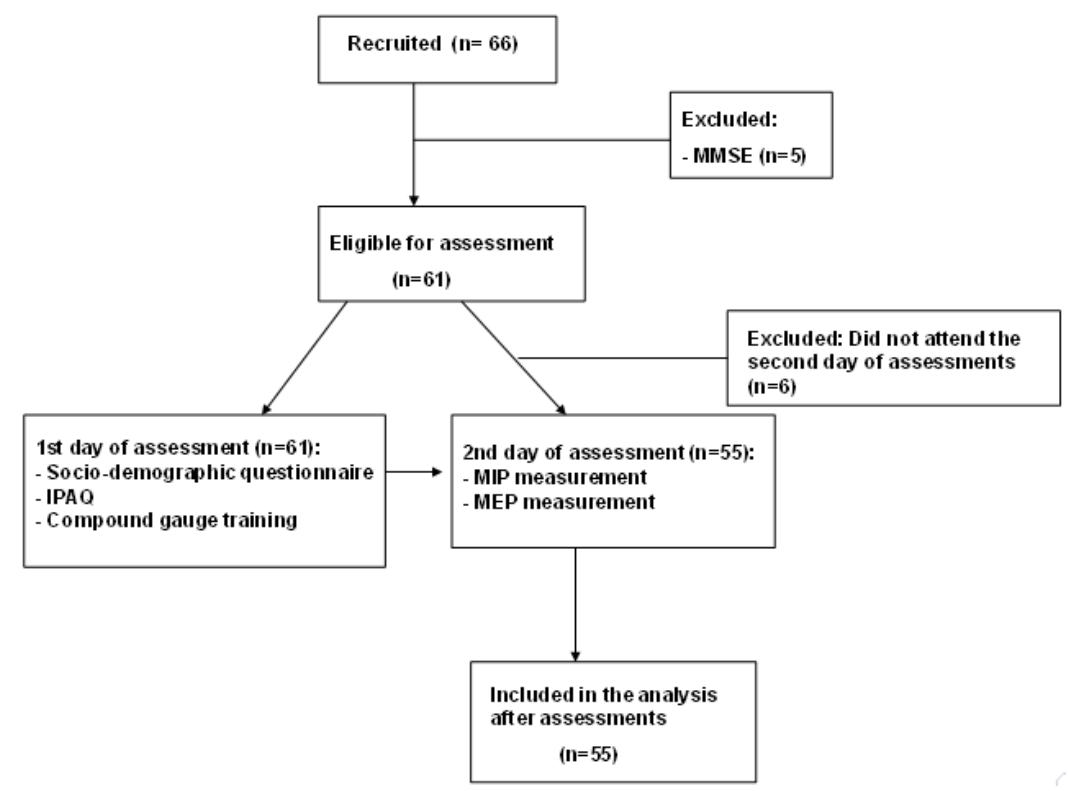

Figure 1. Flowchart for the study participants.

In addition, $70.9 \%$ of the participants regularly performed some level of physical activity, whereas $29.1 \%$ were completely sedentary. Furthermore, $27.3 \%$ of the participants in which the statistical power was adjusted to 0.8 and the $\alpha$ error to 0.05 .

The Kolmogorov-Smirnov test was used to confirm the normality of the data distribution. Descriptive analyses were performed to characterize the sample and analyze the variables. To compare groups, the repeated measures analysis of variance (ANOVA) was used because the data had a normal distribution, and this analysis was followed by Tukey's test. The results are expressed as the mean \pm standard error of the mean. The significance level was set at $5 \%(\mathrm{p}<0.05)$.

\section{Results}

A total of 66 individuals were recruited to participate in the study. Of these individuals, 61 were selected based on the results of the MMSE, but only 55 individuals were considered to be able to complete the remaining questionnaires because 6 individuals did not attend the second day of assessment (Figure 1).

Table 1. The variation among the participants of each age group.

\begin{tabular}{lllll}
\hline Group & Active $\mathbf{n}=\mathbf{1 5}$ & Irreg. Active $\mathbf{n}=\mathbf{2 4}$ & Sedentary $\mathbf{n}=\mathbf{1 6}$ & Total \\
\hline 60 to 69 years & 12 & 20 & 5 & 37 \\
70 to 80 years & 3 & 4 & 11 & 18 \\
\hline
\end{tabular}

The sedentary group performed less than 10 minutes of physical activity per week $(6.9 \pm 2.7$ minutes/week $)$, the irregularly active group performed between 10 and 150 minutes of exercise per week with no regularity in the days of activity (98.1 minutes/week \pm 16.5 ), and the active group performed regular physical activity ( 5 or more days a week) were classified as active, $43.6 \%$ were classified as irregularly active, and $29.1 \%$ were classified as sedentary (Table 1), these individuals had an average of $67.4 \pm 5.3$ years. with at least 30 minutes per session (217.7 \pm 68.3 minutes/week). The study participants in both the active group and the irregularly active group practiced mostly water aerobics and walking.

The MMSE results for the participants were between 22 and 30 points, and the mean score was $25.9 \pm 3.8$ points. 
These results indicated that, in the selected sample, no participants demonstrated impairments in cognitive ability.

The average MIP values for the active group $\left(82.7 \mathrm{cmH}_{2} \mathrm{O}\right)$ and the irregularly active group $\left(80.4 \mathrm{cmH}_{2} \mathrm{O}\right)$ were higher than that recorded for the sedentary group $\left(62.5 \mathrm{cmH}_{2} \mathrm{O}\right)(\mathrm{p}<$ $0.05)$, and there was no significant difference between the individuals who were active or irregularly active (Figure 2).

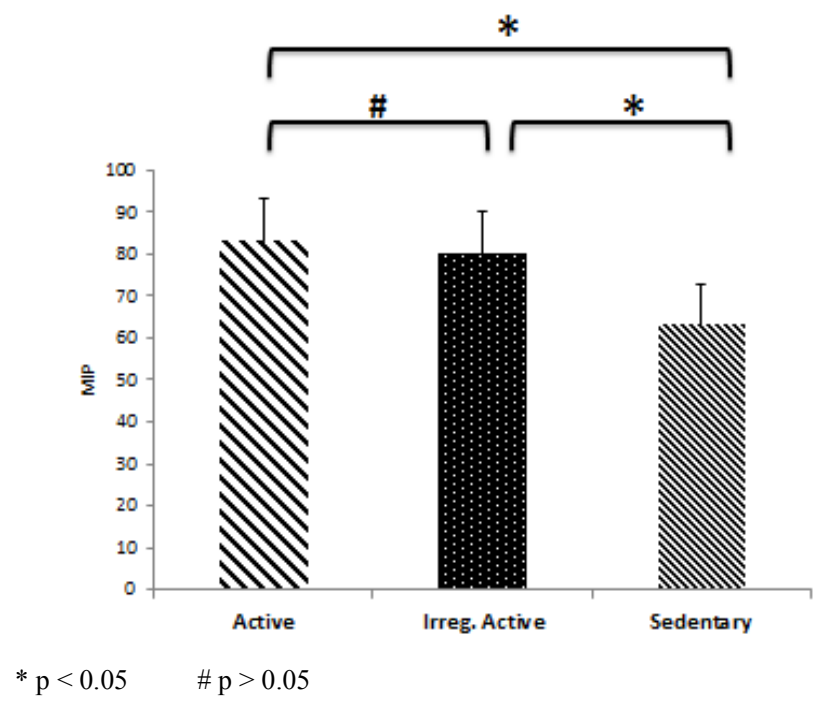

Figure 2. The mean values of MIP obtained for the assessed groups.

The MIP values for the active and irregularly active groups were compatible with our predictions, and there were no significant differences. However, the sedentary group demonstrated MIP values that were $24.8 \%$ below the expected values $(\mathrm{p}<0.05)$ (Figure 3 ).

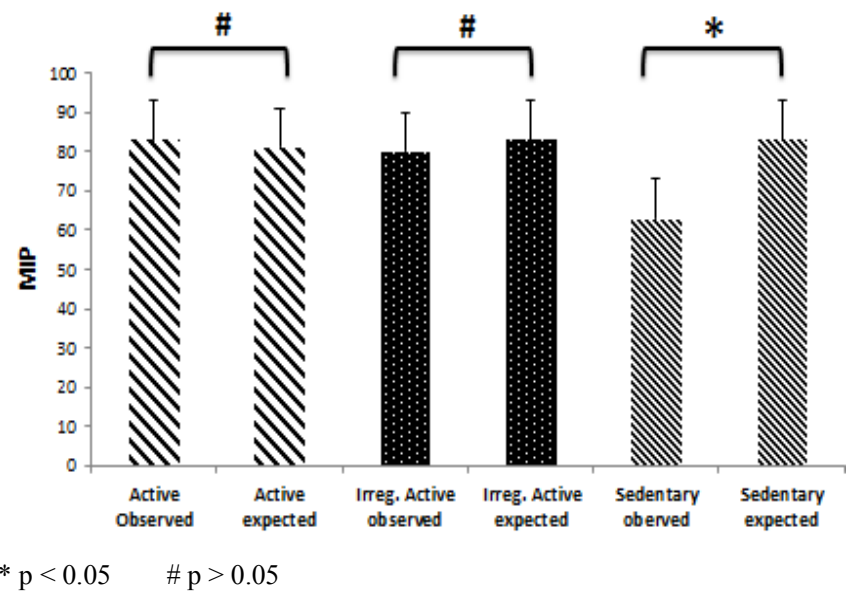

Figure 3. The mean values for obtained and expected MIP in the assessed groups

There were no statistically significant differences between the expected and obtained MEP values $(\mathrm{p}<0.05)$.

\section{Discussion}

This study evaluated elderly participants of both genders (45 women and 10 men). The maximal respiratory pressures (MIP and MEP) were evaluated, and the participants were classified according to the IPAQ as active, irregularly active or sedentary to investigate the level of physical activity influencing respiratory muscle strength in the elderly.

The results demonstrated that the MIP values for the active and irregularly active elderly participants were higher than those of the sedentary participants but were not different from the expected values. These results indicate that even irregular and short-duration physical activity is effective at preserving respiratory muscle function.

Certain authors have suggested that reductions in muscle strength among the elderly may be related to changes in glycolytic and anaerobic enzymes, decreases in capillary density, reductions in diaphragm recoil velocity and tension generation and reductions in muscle mass and the number of muscle fibers, among other factors (Vasconcellos et al., 2004). Furthermore, physiological aging involves the replacement of muscle tissue with fat tissue, and inactivity or immobilization causes a reduction in skeletal muscle mass and power. Thus, these individuals have a lower capacity for sustaining muscular work (endurance) in the skeletal and respiratory muscles (Gorzoni; Russo, 2006).

Changes or reductions in respiratory muscle strength in the elderly represent an important factor in the decline of pulmonary function during the aging process. Moreover, these changes compromise the individual's functional energy reserve, which leads to the development of numerous symptoms associated with aging and limits the capacity and tolerance for exercise. These situations can become more serious when they are associated with other changes or diseases affecting the respiratory and/or cardiovascular system (Zeleznik, 2003 e Ishida et al., 2000).

These results were confirmed in a multicenter study conducted by Enright et al. in 1994, which assessed 4,443 elderly individuals aged 65 years or older and found a progressive loss of respiratory muscle strength associated with age. Moreover, these authors calculated a yearly MIP loss of 0.8 to $2.7 \mathrm{cmH}_{2} \mathrm{O}$, which was more marked in women.

A study by Britto et al. (2005) analyzed respiratory function and compared pulmonary function between adults and the elderly. These authors divided the study participants into three different groups: adults aged between 20 and 59 years, elderly individuals aged between 60 and 69 years and elderly individuals over 69 years of age. The results of this study indicated that lower MIP values were associated with elderly individuals.

Additionally, changes associated with aging can be aggravated by sedentary lifestyles, and the effects of global physical activity on respiratory muscle strength have been well established. Watsford et al. (2005) assessed 77 individuals aged over 64 years who were classified as active or inactive and obtained MIP and MEP values 14 and 25\% higher, respectively, in the active group compared with the inactive group.

Previous studies have demonstrated that respiratory changes due to aging, such as reductions in respiratory muscle strength, can complicate the activities of daily living (ADL) and that a lack of physical activity can worsen the 
loss of respiratory muscle strength. Together, these changes cause a reduction in respiratory pump efficiency and further compromise the performance of exercises, which results in a cycle of negative consequences. Therefore, it is necessary to intervene in groups of older, inactive individuals because they are at a higher risk of exhibiting aging-related complications.

In this context, several studies have evaluated the influence of physical activity or physical training on pulmonary function and respiratory muscle strength. The study by Cook et al. (1989), analyzed 2,250 participants aged 65 years or older and evaluated the relationship between functional capacity, physical activity and peak expiratory flow (PEF). The results showed that individuals who were capable of performing ADL had higher PEF rates, as did individuals who were involved in regular physical activities.

Following the same line of research (McConnel; Copestake, 1999 e Watsford et al., 2005) studied the influence of physical activity on respiratory muscle strength and found that exercise plays an important role in the maintenance of MIP and MEP. Thus, regular physical activity may indirectly improve airway protection because strength gain and increases in PEF can contribute to improved coughing efficiency.

Freitas et al. (2010), evaluated healthy elderly individuals and studied the influence of physical activity and functional levels on parameters of pulmonary function, such as respiratory muscle strength and coughing efficiency. The elderly participants in this study were separated into two groups (active and moderately active), and the results showed that, on average, active elderly individuals had MEP and MIP values that were $13.5 \mathrm{cmH}_{2} \mathrm{O}$ and $16.2 \mathrm{cmH}_{2} \mathrm{O}$ higher in comparison to moderately active individuals, respectively, with an estimated loss of $1 \mathrm{cmH}_{2} \mathrm{O}$ per year.

In addition, the effect of inactivity was evaluated in a study by Cader et al. (2006), which found reduced MIP values in a group of institutionalized and sedentary elderly women in comparison to a group of elderly women who practiced water aerobics. These results suggest that improvements in respiratory muscle strength may be associated with the performance of regular physical activity.

Specific inspiratory muscle training (IMT) has traditionally been recommended for patients with chronic obstructive pulmonary disease (COPD) to improve strength. Few studies, however, have focused on the effects of IMT in older adults without COPD. In this context, Watsford and Murphy (2007) studied an 8-week IMT protocol and concluded that this duration of training increased MIP values by $20 \%$ in elderly individuals aged between 60 and 69 years, demonstrating that older individuals are capable of responding satisfactorily to IMT.

In 2011, Huang et al. reported the effects of 6-week IMT in elderly individuals with and without COPD and concluded that training increases MIP, reduces dyspnea and improves the health-related quality of life of elderly individuals without COPD. IMST benefits subjects with COPD and those without COPD.
With the goal of evaluating IMT in sedentary elderly individuals, Cader et al. (2007) conducted a study on institutionalized elderly individuals and found that the strengthening of inspiratory muscles alone resulted in increases in MIP and functional autonomy among participants.

Furthermore, IMT and global physical training, if practiced regularly, can enhance respiratory function in the elderly through gains in respiratory muscle strength and improvements in functional performance. Additionally, inactivity leads to a more marked loss of respiratory muscle strength, which is associated with poor performance in ADL and a higher incidence of complications.

In the present study, the elderly individuals in the active and irregularly active groups practiced an average of 42.6 and 31.2 minutes of physical activity per day with an average of 5 and 2 sessions of moderate physical activity per week, respectively. To the best of our knowledge, this study is the first to show that irregular physical activity can prevent the loss of respiratory muscle strength in the elderly. As we observed beneficial effects even with the irregular practice of exercises of short duration, these results stress the importance of promoting physical activity in this population.

Thus, these results are reflective of the importance of promoting physical activity among elderly individuals, regardless of whether the exercise level is low or the exercise is integrated with leisure activities. It is noteworthy that the active elderly individuals in this study commonly practiced water aerobics at least twice a week for 30 minutes, which is an activity that many participants consider to be very pleasant.

This study confirmed that sedentary elderly individuals demonstrate marked reductions in MIP compared with expected values. However, there were no differences when the expected values were compared with those obtained in the active or irregularly active groups.

In this study, the number of female individuals in the senior group was higher than the number of male individuals. This prevalence of female individuals was a consequence of the proportion between men and women that frequented the School Health Center and can be partially explained by the "feminization" of the aging process, situation that reflects the higher proportion of women compared to men, according to the Brazilian 2010 Census (IBGE, 2010).

Moreover, the procedures used to assess respiratory muscle strength require the full cooperation of the participant, and therefore, the use of the MMSE for the evaluation contributed to an appropriate selection of elderly individuals, as those for whom cognitive aspects could have interfered with understanding and responding to the questionnaires were excluded.

In summary, the results showed that even individuals who practiced physical activity at levels classified as irregularly active demonstrated good respiratory muscle performance, as they exhibited values that were no different than those predicted for individuals of the same age and gender. In contrast, the sedentary group demonstrated values that were 
below those expected for this population, which highlights the need for preventive guidance in this group.

\section{Acknowledgments}

We would like to thank the staff of the School Health Center and the elderly individuals who participated in the study.

\section{References}

[1] American Thoracic Society; European Respiratory Society. ATS/ERS statement on respiratory muscle testing. Am J Respir Crit Care Med. 2002; 166(4):518-624.

[2] Britto RR, Vieira DSR, Rodrigues JM, Prado LF, Parreira VF. Comparação do padrão respiratório de adultos e idosos saudáveis [Comparison of respiratory patterns between healthy adults and elderly individuals]. Rev Bras Fisioter. 2005;9(3):281-7.

[3] Cader SA et al. Comparação da Pimáx e da qualidade de vida entre idosas sedentárias, asiladas and praticantes de hidroginástica [Comparison of MIP and quality of life among elderly women who are sedentary, institutionalized or who practice water aerobics]. Fit Perf J. 2006; 5 (2):101-108.

[4] Cader, S.; Silva, E. B.; Vale, R.; Bacelar, S.; Monteiro, M. D.; Dantas, E.; Efeito do treino dos músculos inspiratórios sobre a pressão inspiratória máxima e a autonomia funcional de idosos asilados. [Effect of inspiratory muscle training on the maximal inspiratory pressure and functional autonomy of institutionalized elderly people]. Rev. Motricidade. 2007; 3(1): $279-288$

[5] Chaimowicz F. Epidemiologia e o envelhecimento no Brasil [Epidemiology and aging in Brazil]. In: Freitas E V et al. Tratado de Geriatria e Gerontologia [Treatise on Geriatrics and Gerontology]. 2 ed. Rio de Janeiro: Guanabara-Koogan, 2006, pp 106-130)

[6] Cook NR, Evans DA, Scherr PA, Speizer FE, Vedal S, Branch LG, et al. Peak expiratory flow rate in an elderly population. Am J Epidemiol. 1989;130(1):66-78

[7] Craig CL et al. International Physical Activity Questionnaire: 12 - Country Reliability and Validity. Med. Sci. Sports Exerc. 2003; 35 (8): 1381-1395.

[8] Doherty TJ Invited review: Aging and sarcopenia. J Appl Physiol. 2003; 95(4): 1717-27.

[9] Enright PL, Kronmal RA, Manolio TA et al. Respiratory muscle strength in the elderly: correlates and reference values. Cardiovascular Health Study Research Group. Am J Respir Crit Care Med. 1994; 149: 430-438.

[10] Freitas FS, Ibiapina CC, Alvim CG, et al. Parreira Relação entre força de tosse e nível funcional em um grupo de idosos [Relationship between cough strength and functional level in a group of elderly individuals]. Rev Bras Fisioter. 2010; 14 (6): 470-476.

[11] Gorzoni ML, Russo MR. Envelhecimento respiratório [Respiratory aging]. In: Freitas EV et al. Tratado de Geriatria e Gerontologia [Treatise on Geriatrics and Gerontology]. Rio de Janeiro: Guanabara- Koogan, 2006, pp 340-343.
[12] Green M, Road J, Sieck GC, Similowski T. Tests of Respiratory Muscle Strength. Am J Respir Crit Care Med. 2002; 166 (4):528-547.

[13] Huang CH, Yang GG, Wu YT, Lee CW. Comparison of inspiratory muscle strength training effects between older subjects with and without chronic obstructive pulmonary disease. J Formos Med Assoc. 2011; 110(8): 518-26.

[14] Instituto Brasileiro de Geografia e Estatística - IBGE [Brazilian Institute for Geography and Statistics - IBGE]. Projeção da população do Brasil por sexo e idade para o período 1980-2050 [Brazilian population projections by gender and age for the period from 1980 to 2050]. Revisão [Review] 2004.

[15] IBGE. Contagem da População [Population Count] - 2010. Available at: <www.ibge.gov.br $>$, accessed on October 05, 2013.

[16] Ishida K, Sato Y, Katayama K, Miyamura M. Initial ventilatory and circulatory responses to dynamic exercise are slowed in the elderly. J Appl Physiol. 2000; 89:1771-1777.

[17] Jacob Filho W, Souza RR de. Anatomia e fisiologia do envelhecimento [Anatomy and physiology of aging]. In: Papaléo Netto M. Geriatria - fundamentos, clínica e terapêutica [Geriatrics - fundamentals, clinic and therapy]. 1. ed. São Paulo: Atheneu, 1994, pp 31-40.

[18] Jardim JR, Ratto OR, Corso SD. Função pulmonar [Lung function]. In: TARANTINO, A. B. Doenças pulmonares [Lung diseases]. 5. ed. Rio de Janeiro: Guanabara Koogan, 2002, pp 113-123.

[19] McConnell AK, Copestake AJ. Maximum static respiratory pressure in healthy elderly men and women: issues of reproducibility and interpretation. Respiration. 1999; 66(3):251-8.

[20] Neder JA, Andreoni S, Lerario MC, Nery LE. Reference values for lung function tests II: maximal respiratory pressures and voluntary ventilation. Braz J Med Biol Res. 1999; 32(6):719-27.

[21] Nelson ME, Rejeski WJ, Blair SN, Duncan PW, Judge JO, King AC et al. Physical activity and public health in older adults: recommendation from the American College of Sports Medicine and the American Heart Association. Med. Sci. Sports Exerc. 2007; 39(8):1435-45.

[22] Nikolić M, Vranid TS, Arbanas J, et al. Muscle loss in the elderly. Coll Antropol. 2010; 34 (Suppl 2): 105-108.

[23] Pardini R et al. Validação do questionário internacional de nível de atividade física (IPAQ - versão 6): estudo piloto em adultos jovens brasileiros [Validation of the International Physical Activity Questionnaire (IPAQ - version 6): a pilot study with Brazilian young adults]. Rev. Bras. Ciên. e Mov. 2001; 9 (3): 45-51.

[24] Papaléo Netto M. O estudo da velhice: histórico, definição do campo e termos básicos [The study of old age: history, field definition and basic terms]. In: Freitas E V et al. Tratado de Geriatria e Gerontologia [Treaty of Geriatrics and Gerontology]. 2 ed. Rio de Janeiro: Guanabara-Koogan, 2002, pp 02-12.

[25] Papaléo Netto M. Gerontologia: a velhice e o envelhecimento em visão globalizada [Gerontology: a general view of old age and aging]. Rio de Janeiro: Atheneu, 2005. 
[26] Paschoal S M P. Qualidade de Vida na velhice [Quality of life in old age]. In: Freitas E V et al. Tratado de Geriatria e Gerontologia [Treatise on Geriatrics and Gerontology]. Rio de Janeiro: Guanabara Koogan, 2 ed., 2006, pp 131-153.

[27] Peluso MAM, Andrade LHSG. Physical activity and mental health: the association between exercise and mood. Clinics. 2005; 60: 61-70.

[28] Silva LCC, Rubim AS, Silva LMC. Avaliação funcional pulmonar [Lung function assessment]. São Paulo: Revinter, 2000 .

[29] Tolep K, Higgins N, Muza S, et al. Comparison of diaphragm strength between healthy elderly adults and young men. Am J Respir Crit Care Med. 1995; 152(2):677-82.

[30] U.S. Census Bureau. State and national population projections
Available http://www.census.gov/population/www/projections/popproj.h tml. Accessed 15 November 2011.

[31] Vasconcellos JAC, Britto RR, Parreira VF, Cury AC, Ramiro SM. Pressões respiratórias máximas e capacidade funcional em idosas assintomáticas [Maximal respiratory pressures and functional capacity in asymptomatic elderly women]. Fisioter Mov. 2007; 20(3):93-100.

[32] Watsford ML, Murphy AJ, Pine MJ, Coutts AJ. The effect of habitual exercise on respiratory muscle function in older adults. J Aging Phys Act. 2005;13(1):34-44.

[33] Watsford ML, Murphy AJ, Pine MJ. The effects of aging on respiratory muscle function and performance in older adults. $\mathrm{J}$ Sci Med Sport. 2007; 10(1):36-44.

[34] Zeleznik J. Normative aging of the respiratory system. Clin. Geriatr. Med.. 2003; 19:1-18. 